Corresponding Author: Nafiset K Kuprina

nafiset.kuprina@yandex.ru

Received: 12 March 2019

Accepted: 17 April 2019

Published: 25 April 2019

Publishing services provided by Knowledge E

(c) Zara K. Meretukova et al. This article is distributed under the terms of the Creative Commons

Attribution License, which permits unrestricted use and redistribution provided that the original author and source are credited.

Selection and Peer-review unde the responsibility of the Individual and Society in the Global Era Conference Committee.

\section{Environmental Education in the Teaching and Learning Process in the Context of Enhancing the Educative Learning Function}

\author{
Zara K. Meretukova1, Aida R. Chinazirova ${ }^{2}$, Nafset S. Blyagoz ${ }^{3}$, Nafiset K \\ Kuprina ${ }^{3}$, and Bella K. Dzhabatyrova ${ }^{3}$ \\ ${ }^{1}$ Doctor of Pedagogical Sciences, Professor, Professor of the Department of General Pedagogy \\ of Adygea, State University, Russia, Maykop \\ ${ }^{2}$ Candidate of Pedagogical Sciences, Associate Professor, Associate Professor at the Department \\ of Music and Choreography of the Adygea State University, Russia, Maykop \\ ${ }^{3}$ Candidate of Pedagogical Sciences, Associate Professor, Associate Professor of the Department \\ of General Pedagogy of Adygea, State University, Russia, Maykop
}

\section{Abstract}

The article substantiates the relevance of the problem of environmental education and discusses various approaches to its solution. The author's definition of the concepts "ecology" and "environmental education" is proposed. The necessity of the syncreticism of environmental and moral-spiritual education is substantiated. Means, methods, pedagogical conditions and stages of environmental education in the teaching and learning process are proposed in the context of enhancing the educative learning function.

Keywords: ecological crisis; ecological education; syncretism of environmental and moral education; emotional value attitude; pedagogical conditions.

\section{Introduction}

It is believed that the most important cause of the death of the once most powerful Western Roman Empire is the moral decay of people and, above all, the powerful people. Individual states and empires died in those times. In the modern world, death threatens all of humanity, and not only because of the moral crisis, but also because of the ecological one, which is a consequence of the first. It can be argued that the main feature of the modern era is "a systemic crisis that has engulfed three of the most important spheres of spiritual life - science, religion, education" [1]. But it's not the only thing. There is a crisis in the social, political, geopolitical, economic, environmental spheres, today they are all the consequences of the moral decay of people and above all the power 
and capital of the haves. There are many facts of reality, testifying to this. One can cite facts that reflect the ethical problems of various fields of science: biology, genetics, medicine, genetic engineering, associated with the manipulation of the human psyche. In some sources, the problem of the obsession of a scientist is cited as one of the ethical problems [2]. And no matter what practical steps are taken by the countries participating in the Kyoto Protocol to introduce environmentally sound technologies, they are all a drop in the bucket. The problem is globalism and globalization, which gave rise to "bolonization", "egezation", "computerization", "internetization”, "competitionazation", contributing to the moral decay of the majority of the younger generation and therefore their devil-may-care attitude to environmental issues. Some scientists, both foreign and domestic, express their concern about the situation in the world. Examples of the concern of the progressive part of humanity with the environmental crisis that had a serious impact on public consciousness in Western Europe are the emergence of the green movement, international educational projects, the development of a new paradigm of civilization, etc., aimed at promoting the formation of environmental consciousness and the identification of ways and means of forming planetary consciousness and human thinking. The question is raised of how to make human interaction a controlled process in accordance with the laws of nature and the cosmos, with the laws of the cosmo-earth evolution [3]. However, all the concerns of scientists and all international projects will not take force, first, without the appropriate educational policy of the state, and, second, without enhancing the educative function of education. Our special article is devoted to the latter, and the interested reader will find more detailed information in it [4].

As emphasized in the philosophy of science, modern science has assumed responsibility for overcoming the environmental crisis becoming one of the sources of global crises and playing the role of "the servant of technology". Scientists have recognized that the increased anthropogenic impact on the environment, technological pressure on the world led to the beginning of the era of global environmental crises [2] Their concern is also caused by the fact that the thoughtless and egoistic use of technology, the priority of material well-being over the moral and spiritual well-being of peoples led to the fact that "the very physical and mental health of a person, his gene pool and cultural foundation were in danger" [6]. Firstly, to overcome the consequences of all this, it is necessary, to abandon the old forms of thinking and to develop new approaches to the vision of the world, from the complete subordination of man to the forces of nature [3], secondly, to enhance the nurturing function of education and, in particular, environmental education in learning process. However, the traditionally proposed formation of environmental 
knowledge, promotion of ecological awareness is not enough for environmental education. The most important thing in solving environmental problems, as well as others, is the transformation and implication of acquired knowledge, skills and experience in the value-sense sphere of the personality of the students. And this seems to us an eternal and most difficult problem.

\section{Research Methods, Materials and Discussion}

As is evident from the title of the article, the object of its discussion is to enhance the educative learning function, and the subject is environmental education in the teaching and learning process in the context of enhancing the educative learning function. Analysis, comparison, observation, modeling of the educational process, questioning, experiment, survey methods, synthesis were used as research methods. In addition to the general philosophical provisions that are the methodological basis of any research, our study was based on such methodological tenets of pedagogical science as the unity of training and education and the unity of the substantive and procedural aspects of training. In addition, the study focuses on such methodological approaches as structural system, anthropological, synergistic, hermeneutic.

The problems of the ecological crisis and their overcoming have always attracted the attention of both scientists and the public. They began to be especially actively discussed in the scientific literature in the 1990s. Particular emphasis was placed on such fundamental concepts of the ecological plan as harmony and unity of the natural and spiritual principles, the worldview of holism, consideration of reality as an integrative whole, "deep ecology" as a synonym for a new paradigm, the need for a person to realize his involvement in the whole world, man-microcosm macrocosm etc. [5]. All this is considered from the standpoint of holism, systematic approach and interpretation of the problems of the ecological crisis in a broad cosmoplanetary context, which fits, from our point of view, in the ideas of post-non-classical scientific picture of the world and synergetic approach in science and education. And before considering the issue of different approaches to solving environmental problems, let us dwell on the concept of "ecology" (from the Greek, Oikos - housing, habitat, home, homeland), defined in some sources as a special scientific area of biology that studies the relationship between animals and plants with their natural environment [6], in others as a science that studies the relationship of organisms with each other and with their habitat [7]

The ecology, which initially sought to study and understand only the issue of adapting various living organisms to each other and to the natural environment, but did not 
consider social life and its negative impact on the biosphere, had to expand its sphere of influence and the subject of its knowledge, recognize that man is the cause of the violation balance of natural space processes.

The question of the place and role of education in solving environmental problems has also passed a certain path of its development. On this path, the problem of environmental education, the acquisition of ecological knowledge, and especially integrated interdisciplinary, forming a systemic vision of the world, came to the fore. Then it became necessary to study such complex personal formations as environmental awareness, ecological culture, green-conscious behavior, etc. For example, back in the 70 s of the last century, I.D. Zverev put forward the problem of transition from nonconsumptive education to environmental education and education of schoolchildren, which marked a new approach of solving environmental problems - the formation of such personal qualities as the relationship of man to nature and for this purpose the use of the potential of interdisciplinary connections in learning [8]. And even earlier, in the 30s of the last century, some authors (Aldo Leopold) put forward the question of the need to solve environmental problems in the context of moral principles, which is very close to our vision of the problem. At the same time, morality was interpreted from a biological point of view as a restriction of freedom of action in the struggle for existence, and from a philosophical one - as a differentiation of social and antisocial behavior [9]. Later, in the late 80 s of $X X$ century, the concept of global evolutionism took shape, taking into account the dynamics of the development of the inorganic, organic and social worlds and based on the idea of the unity of the universe and on the idea that the entire Universe is a huge evolving system. Global evolutionism includes four types of evolution - cosmic, chemical, biological and social, combining them with genetic and structural continuity [2]. The emergence of such a scientific field as synergetic also testifies to the search for global and general evolutionary laws that universally unify the development of systems of different nature. It was the ideas of synergetics, along with the theory of nonstationary Universe and the concept of the biosphere and noosphere, that contributed to the substantiation of the theory of global evolutionism, in which the problem of coevolution becomes fundamental, i.e. coordinated coexistence of nature and man, on the solution of which depends the problem of the survival of humanity. This may explain the emergence of such disciplines as environmental philosophy, social ecology, ecology of culture, ecology of science, environmental ethics, etc.

The approach of the Canadian scientist M. Yagan to the problem we are considering is of interest, the leitmotif of which is the thesis that any living creature exists and functions 
on five harmoniously combined vibrational levels: physical, intellectual, emotional, spiritual, mental, and environmental [10]. The ecological level intersects with all the others. The framework of one article does not allow considering all of these levels, therefore we note that, revealing the essence of the ecological level, the author emphasizes that all efforts for a holistic, healthy, adequate and harmonious state of a person are aimed at building its proper relations with the environment, including such basic aspects such as physical, professional, social, family aspects, the aspect of relationships with parents, the aspect of marital relations and the aspect of personality ecology [10]. The latter is understood as the ability of a person to interact effectively with the outside world, and in this connection, the author makes his discourses about two such person's manifestations as essence and personality. The essence is what a person inherits at birth, what is stored in it as a treasure. Personality is a state achieved by the development and manifestation of an entity; it is an entity revealed as a result of contact with the external world. The essence is potential, the personality is actual.

The following definition can be given to the concept "ecology" proceeding from the main theses, the above-mentioned integrative disciplines in ecology and theses of parascientific (esoteric) knowledge: - this is the field of culture and science, including the relationship between living organisms and the cosmic-earth nature and with each other, based on the ideas of unity in the universe of inorganic, organic, social and moralspiritual worlds, unity and purity of body, soul, spirit and actions person. From this definition, the definition of the concept of "environmental education" can be derived: it is a process of purposeful, systemic and systematic formation of the need and readiness of the individual to understand and realize the eternal involvement of man in cosmic phenomena and hence the need for purity and unity of the body-soul-spirit and actions in relation to nature and people.

In connection with the "fashionable" competence-based approach, publications have appeared that raise issues of the formation of environmental competence in recent decades. Their analysis suggests that they address all the same traditional questions: the development of theoretical knowledge and practical skills in ecology, environmental values, the development of environmental meanings in the course of personally and socially significant environmental activities and the acquisition on this basis of experience in solving environmental problems [11]. Competence-based approach leaves the moral and spiritual education without attention, without which it is impossible to solve environmental problems, or at best formally declares it. This, like many other things, is explained by the fact that we do not have an educational process strategy as N.Ye. Shchurkova rightly notes, just as there is no state development strategy, instead of a 
clear theory of upbringing, we have a cumulative totality of a multitude of bureaucratic provisions that randomly prescribe to the school questionable and even harmful indications regarding the development of personality [12].

All academic disciplines, both in school and in a higher educational institution, have upbringing potential, one to a greater extent, and the other to a lesser extent. This also applies to environmental education in the educational process. Our long-term research and long-term experience of professional and pedagogical activity allowed us to define and formulate a number of pedagogical conditions for enhancing environmental education in the educational process: 1) teacher observance of the syncretic nature of environmental and moral and spiritual education; 2) increasing the frequency of updating environmental problems and the inclusion of trainees in the emotional-axiological experience (living) of these problems; 3 ) actualization of students' thoughts when discussing ethical and environmental issues; 4) ensuring the awareness of the trainees of the eternal human involvement in cosmoplanetary phenomena, to the universe; 5) the formation of a suggestive culture of a school teacher and a university teacher, suggesting, among other things, the ability to enhance the resource-functional essence of problem-based learning, and for this purpose possession of its theory and practice.

These conditions are interrelated. The implementation of other conditions largely depends on the latter condition, that is, on the formation of a suggestopedic culture.

As a hypothesis of the study, we have suggested that the enhancing of environmental education in the educational process will be effective and will give some positive results if the complex of the above conditions is met. Their implementation in the educational process assume such types of the teacher activity as diagnosis, prediction, planning, designing, organizing, suggestic, communicative and analytical and evaluation activities. It is not possible to disclose all the above pedagogical conditions in a single article. We will focus only on some of them, but at the beginning we will point out that for the implementation of all formulated conditions and especially such conditions as the frequency of actualization of environmental problems and the inclusion of students in the emotional-value "living" of the facts of the ecological crisis, at the design stage the following are revealed: 1 ) the convergence points of each topic of the course (in our case, the disciplines of the magistracy "Modern Problems of Science and Education", "History and Methodology of Science", "Pedagogy of Higher Education") with the problems of ecological and moral and spiritual crisis; 2) methods and techniques for the transformation and implication of the cognitive, i.e. assimilable knowledge, skills, experience of creative thinking and creative activity in the emotional value. The latter seems to us, as was emphasized above, to be the most difficult in pedagogical activity in general. For 
example, studying the themes "Synergistic approach in science and education" or "Postnon-classical scientific picture of the world" on the course "Modern problems of science and education" and discussing the theses of systems theory, the emphasis is placed on the fact that these approaches focus on a single system values, collectivism, understanding of a person as part of a whole, as part of a system, as a microcosm in the macrocosm. The method of heuristic discussion of problem-based learning switched the discussion smoothly into anthropological problems of science and education, for example, problems of understanding human nature in modern science, understanding and interpreting human consciousness in their traditional and non-traditional interpretations, as well as such spiritual qualities of a person as love, joy, good mood in their anthropological interpretation, etc. The discussion of these problems causes an association with certain scientific and everyday theses and disputes on them, while the discussion of these theses is integrated into the context of environmental issues, converging them with the ethical concepts of Good, Beauty, Truth. The convergence of two inseparable aspects - the ethical and environmental is systemic, systematically updated in nature. And what is very important, the problem of the ecological crisis is also considered differentially in the context of Good, in the context of Beauty and in the context of Truth, i.e. ecology as ethical, as aesthetic and as an intellectual problem. Discussion of this and other issues expands the possibilities of updating not only environmental and moral-spiritual problems, but also social, political, geopolitical, economic, etc.

For the realization of such a pedagogical condition, such as ensuring students' awareness of eternal human involvement in cosmoplanetary phenomena, the subject of rethinking in science of understanding the nature of man, his integral essence, the problem of man of the microcosm in the macrocosm and in connection with this such question as unity and purity of the body, soul, and the spirit and actions of man in parascientific (esoteric) interpretation is subject to discussion.

Comparing the approaches of modern scientists to these problems and their parascientific explanation, the trainees pay special attention to the point of view that mental creativity and morality are organically woven into a single system of universal information interaction, including gravitational, biological, electromagnetic, intramolecular and intranuclear fields, which are the common forces of a single information field. The emphasis put on the assumption that an ideological field, formed by education, upbringing and the environment and warmed by high moral and spiritual emotions, is an intermediary between common forces and human consciousness [3]. This point of view is unambiguous in parascience. Anyhow, it is necessary to strive for the awareness of the educated, that man is a kind of ecosystem, involved in the space - earth ecosystem. For example, 
considering the latest scientific discoveries about the wave genetic code, such science data is being discussed that swear and indecent words litter the information field and cause great harm, that they cause DNA mutation and can cause birth of freak children, self-destructive processes embedded in the human genome by his speech.

One of the effective means of enhancing the educational function of education in general and the implementation of the above pedagogical conditions of environmental education in the educational process is, as our experience shows, the preparation and organization of work of students (in our case, undergraduates) on the analysis of specially selected educational and scientific texts on environmental problems. Carrying out such work of the trainees on the analysis of the text at the training session included three stages: the design stage, the stage of implementation, analytical and evaluative phase. At the design stage, the activities of the teacher and trainees were determined. When designing and constructing the educational process, we proceeded from the methodological postulate of pedagogical science on the unity of the substantive and procedural aspects of learning, which focuses on activating not only the knowledge and operational components of educational content, but also the emotional value sphere of the students' personality. This implied the active use of methods and techniques of problem-based learning. The main content of the design stage included: 1) selection of texts on the environmental problem and the definition of curriculum topics in which these texts can be integrated; 2) determination of the methods of convergence of questions and tasks with the realization of the syncretism of environmental, moral and spiritual education; 3) compiling a system of questions of a different nature (problem, sub-problem, divergent, convergent, evaluative, rhetorical, counter-questions, counter-arguments), for organizing a heuristic conversation on the text, which is close to a dispute, but not identical, because the theory of problem-based learning with its own intricacies, psychological nuances lies at the heart of the heuristic conversation (it is also partly the search method). 4) the choice of methods and techniques of learning, including students in active and interactive activities, including techniques, questions to ensure the syncretism of environmental and moral problems; 5) the choice of forms and types of activities of trainees in the training session; 6) a selection of maxims of thinkers of the past, as well as ethnopedagogical maxims, proverbs, sayings, various points of view in science, etc.

The stage of conducting text analysis classes was aimed at the inclusion of trainees into active and interactive activities in understanding the nature and importance of the issues discussed. Different types of trainee activities were used for this (frontal, group, 
paired forms of work; reasoning, reflection-essay (oral, written), introduction to the discussion, implementation of intradisciplinary and interdisciplinary connections, expressing one's point of view, a reference to facts of reality, a link to theoretical knowledge, interdisciplinary communication, argumentation, evaluation, etc.). All this was aimed at the formation of general cultural and general professional competencies. The organization of this stage is partially disclosed above when considering the pedagogical conditions of environmental education in the teaching and learning process, therefore, here we present only some fragments: on the topic "Anthropological problems in science", considering such one as the problem of understanding and interpreting the nature of human consciousness, different approaches were used: S. Freud, C. Jung, Pierre de Chardin, Murat Yagan and others. Converging such problems as a person - a microcosm in the macrocosm, a person's involvement in cosmic-earth phenomena, a synergistic approach, systems theory, the trajectory of their discussion was derived on the concepts of "collectivism", "unity", "conscience", on their essence and significance in the modern world, on the problem of true and false patriotism, etc. and their place in solving environmental problems. For example, the theses that "conscience is the highest form of consciousness, the amount of conscience is directly proportional to the level of personality development" (I.P. Podlasy), or another thesis from quantum physics that human consciousness is connected with cosmic consciousness and responds to cosmic processes, it is a powerful factor shaping many terrestrial processes. The discussion of such problems made it possible to update the ethical aspects of the environmental crisis.

The next stage of the text analysis training class is the inclusion of trainees in summarizing the lesson. It is one of the most important attributes of the educational process and should be subject to design and organization. The inclusion of trainees into such an activity is the propaedeutical stage of the formation of such general cultural competence, as the readiness of a future specialist to critically analyze and evaluate the studied objects, phenomena, facts of reality, events, and approaches. To include students in the summing up of the lesson, the teacher must ensure their ability to differentiate between formal and meaningful reflection, as well as to understand that formal reflection is characterized only by the exchange of subjective emotional sensations ("I liked...", "everyone worked well", etc.), while meaningful reflection involves, first, a critical analysis and assessment of the quality of the class, the quality of the whole group, and secondly, a generalization of key theses, concepts, points of view on the problem under discussion, approaches to it, expressing their own attitude to certain theses, points of view. 


\section{Conclusion}

Thus, environmental education in the learning and teaching process in the context of enhancing the educative learning function involves compliance with the totality of such pedagogical conditions as the syncretism of environmental and moral and spiritual education, the frequency of updating environmental problems and the inclusion of students in the emotional and axiological experience of these problems, actualization and activation of their thinking, reasoning and controversy when discussing environmental and ethical issues, ensuring the awareness of students of the eternal involvement of man in the universe, the formation of the suggestopic culture of the teacher. Among other things the latter requires the ability, need, readiness and ability of the teacher to convince, "provoke" the intellectual and emotional-value activity of the trainees. The obtained data of the used evaluation tools, as well as survey and diagnostic research methods, allow stating that the implementation of these pedagogical conditions yielded certain positive results, and this was manifested in the improvement of the quality of cognitive, motivational, and emotional-value indicators in the trainees compared to their initial state. This suggests that the correctness of the research hypothesis has been confirmed.

\section{References}

[1] Gershunsky, B.S. (1997). Education in the third Millennium: the harmony of knowledge and belief (predictive hypothesis of educational triumph). Moscow: Moscow Psychological and Social Institute.

[2] Leshkevich, T.G. (2006). Philosophy of science: instructional medium. Moscow: INFRA-M.

[3] Yarkina, T.F. (1996). Man as an object of social pedagogy and social work: theoretical and methodological aspect (in the context of world experience). Solikamsk.

[4] Meretukova, Z.K., Chinazirov, A.R., Shekhmirzova, A.M. (2018). Enhancing educative function of training as a problem of pedagogical science and education. Bulletin of Adyghe State University. Series "Pedagogy and psychology", 2.

[5] Priorities of modern pedagogy. Materials of the international pedagogical project P. E. A. C. E. Rukov. E. Nordland. - M., 1993.

[6] Gusinskiy, E.N, Turchaninova, Yu.I. (2003). Introduction to the philosophy of education. Moscow: Logos.

[7] Philosophical encyclopedic dictionary. (2002). Moscow: Infra-m. 
[8] Zverev, I.D. (1993). The problems of environmental education in schools and practical activities of students in the field of nature protection. Moscow: Knowledge.

[9] Volsk, D. (1979). Methods of education. In Tendency of education on environmental issues. Paris: UNESCO.

[10] Yagan, M. (2015). The book about the Caucasian longevity and well-being. Maykop: LLC "Quality".

[11] Ermakov, D.S. (2009). Formation of environmental competence of students. Moscow: MIOD.

[12] Shchurkova, N.E. (2018). Horizon of education. Moscow: ITRK publishing house. 